\title{
EDITORIAL Hurricane Katrina: The Infarcts Beyond the Storm
}

\author{
Carl J. Lavie, MD, Thomas C. Gerber, MD, and William L. Lanier, MD
}

A $t$ the 4-year anniversary of Hurricane Katrina, the devastation of this August 29, 2005, storm and its aftermath still affect the lives of many residents and medical personnel in New Orleans, Louisiana, and the surrounding areas along the Mississippi and Alabama Gulf coasts. ${ }^{1}$ Katrina was a powerful category 3 hurricane, whose sustained winds exceeded $125 \mathrm{mph}$ at landfall. It was the sixth strongest hurricane ever recorded, and the third strongest to make landfall in the United States. ${ }^{2}$ Katrina's damaging force extended for $>100 \mathrm{mi}$ from the storm's center. It was the costliest hurricane in US history, with total cost estimated at $>\$ 150$ billion, as well as one of the deadliest in the US, claiming $>1800$ lives in 7 states. More than 1500 of those deaths occurred in Louisiana.

Hundreds of thousands of survivors experienced the loss of family members and friends, homes, schools, churches, and pets, in addition to their health care institutions. Hurricane Katrina inflicted an enormous and enduring physical, psychological, emotional, and social burden on the affected communities, and we are beginning to see reports on some of the intermediate and long-term health consequences of this burden.

In this issue of Disaster Medicine and Public Health Preparedness, Gautam et $\mathrm{al}^{3}$ from Tulane University Medical Center in New Orleans report that their medical center experienced a dramatic, 3-fold increase in patients who presented with myocardial ischemia and myocardial infarction (MI) during the 2 years following February 2006 (when the authors' institution resumed complete onsite cardiac catheterization services), and this increased incidence of MIs persisted for the entire 2-year period. The investigators also found, between years 1 and 2 of their study period, a shift in the overall socioeconomic status of patients presenting with acute MI, toward a population that was more commonly uninsured, unemployed, and medically noncompliant. The investigators suggest that this shift was due to a true change in health-related behaviors among New Orleans residents, and not just simple redistribution of the care of uninsured and otherwise underprivileged individuals from other health care facilities to Tulane Medical Center after Katrina.
These results point to an important but often overlooked effect of natural disasters: the delayed medical consequences. ${ }^{4,5}$ As such, Gautam and colleagues' article deserves close examination, not only to appreciate its implications for future disaster medicine research but also to understand how psychological stress and other "triggers" for MI, disruption of normal lifestyles, and logistical factors and sampling techniques may have influenced their findings. It is hoped that research such as that of Gautam et al will help identify solutions for this public health problem that can be tested for efficacy in future disasters.

\section{PSYCHOLOGICAL STRESS AS A RISK FACTOR FOR CARDIOVASCULAR DISEASE}

New Orleans is affectionately known as "the Big Easy," in part because of the relaxed lifestyle that is a part of New Orleans' heritage and culture. This lifestyle was severely disrupted and supplanted by one fraught with uncertainty, fear, and stress as a result of the devastation of Hurricane Katrina. One must assume that psychosocial stress (PSS) played an important role in increasing the health care burden of New Orleans after Hurricane Katrina. Literally and metaphorically, the sunny, blue skies constituting the "calm before the storm" were replaced by the devastation, stresses, and MIs after the storm.

An enormous amount of literature exists on the role of psychological factors and PSS as risk factors for or contributors to cardiovascular disease (CVD). ${ }^{6-8}$ Despite this strong scientific foundation, the relation between PSS and CVD is typically emphasized more by patients and the media than by clinicians, and this may be particularly true for specialists in CVD. This may be because experts in CVD often choose to focus on more easily quantifiable risk factors for CVD instead of the more elusive psychological risk factors and acute and chronic stressors. It is well established that PSS can affect the regulation of the sympathetic nervous system and hemostasis, and thus may play a role in the pathogenesis of myocardial ischemia, acute coronary syndrome (ACS), acute MI, and sudden cardiac death (SCD; Figure 1). ${ }^{8}$

The Hurricane Katrina experience may be an important reminder to take more seriously the complex interaction between psychology and biology in modulating both chronic and acute CVD. 


\section{FIGURE 1}

\section{Several reasons that promote interest in the evaluation and treatment of psychosocial stress in medical practices. CAD, coronary artery disease. Reproduced with permission from the American College of Cardiology. ${ }^{8}$}

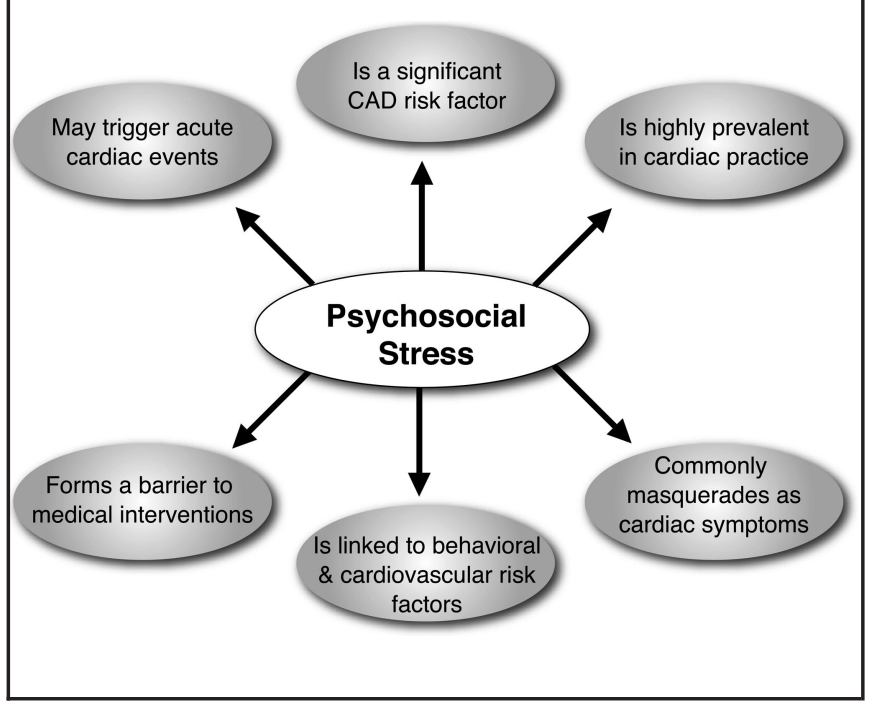

\section{POTENTIAL TRIGGERS OF ACUTE CVD}

Many excellent studies have identified triggers for acute CV events, including ACS and MI, stroke, and SCD (Table 1)..$^{7,9-11}$ The prevalence of many of these triggers was probably increased during or after Hurricane Katrina.

As an example of the effect of triggering, the distribution of acute CV events throughout the day is not random, but instead peaks in the early morning hours. ${ }^{9,10}$ The acute triggering events may stimulate surges in heart rate, vasoconstriction, and arterial blood pressure, and create a hypercoagulable state. Collectively, these may contribute to the rupture of a "vulnerable" plaque or plaque erosion, followed by intracoronary thrombosis (Figure 2; Table 2). ${ }^{7,9-11}$ Early studies suggested that nearly half of patients having an acute $\mathrm{CV}$ event reported possible triggers, and $13 \%$ of those reported a combination of 2 or more poten-

\section{TABLE 1}

\section{Potential Triggers of Acute Cardiovascular Events}

- Emotional stress (anger, anxiety, work-related stress)

- Heavy physical exertion

- Sexual activity

- Lack of sleep

- Overeating

- Population stressors

- Earthquakes

- Wartime missile attacks

- Sporting events

- Emotional Stress (eg, hurricanes, blizzards, etc)

- Other (infections, heavy metals, drugs, seasonal)
FIGURE 2

Potential mechanisms by which a trigger may increase the risk of myocardial infarction or sudden cardiac death. The relative contribution of each physiological change may vary depending on the specific trigger and differences in pathophysiology between infarction and sudden cardiac death. VT/NF, ventricular tachycardia/ ventricular fibrillation. Reproduced with permission from the American Heart Association. ${ }^{10}$

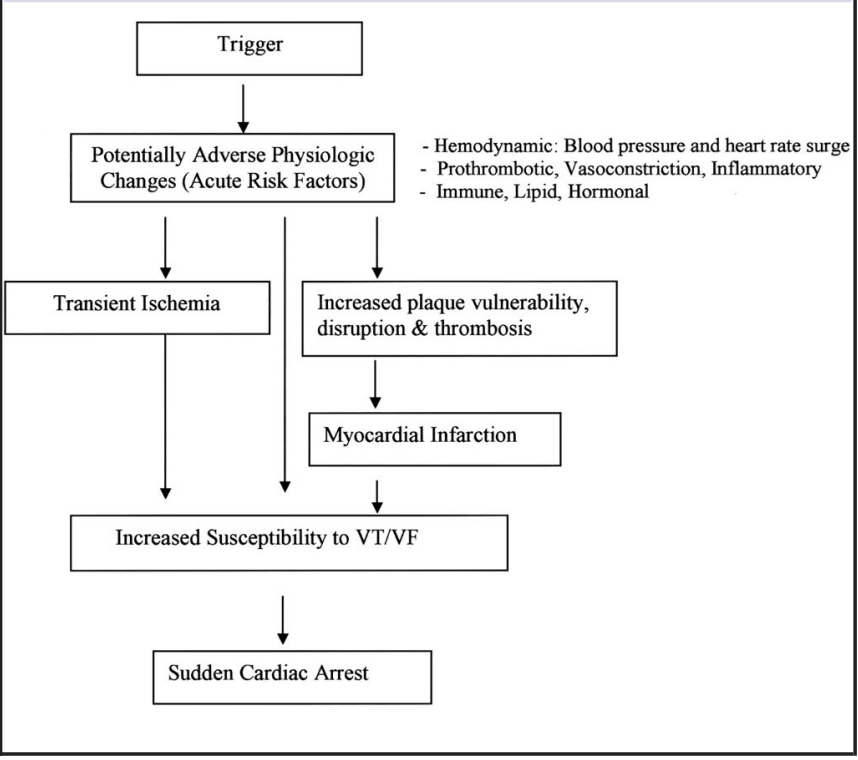

tial triggers. ${ }^{9}$ Common triggers of acute MI included emotional upset, moderate or heavy physical exertion, lack of sleep, or overeating..$^{9,10}$ The public appears to accept the concept that PSS, especially anger, anxiety, and workrelated job stress, can trigger acute $\mathrm{CV}$ events. ${ }^{9-12}$ This situation could be used by public health experts as motivational "leverage" when educating disaster survivors about lifestyles changes that will affect their health positively after a natural disaster.

\section{TABLE 2}

\section{Mechanisms for Triggering Acute Cardiovascular Events}

\section{A. Biomechanical}

1) Increased blood pressure and pulse pressure

2) Increased flow-generated endothelia sheer stress

3) Activation of sympathetic nervous system (SNS)

B. Prothrombotic

1) Platelet activation by SNS

2) Increased blood viscosity

3) Reduced plasma volume

4) Increased fibrinogen

5) Endothelial dysfunction

C. Vasoconstriction

D. Pro-arrhythmia

1) Direct neurocardiac impact

2) SNS activation

3) Myocardial ischemia 
Stressors to not just individuals but entire populations are also a potential trigger of acute $\mathrm{CV}$ events. ${ }^{7,10,11}$ For example, wartime missile attacks, ${ }^{13}$ unanticipated terrorist attacks, ${ }^{14}$ and earthquakes ${ }^{15,16}$ have been associated with an increased incidence of acute CV events. During the missile attacks on Israel in 1991, the incidence of nonfatal MI and SCD doubled. ${ }^{13}$ During the first 2 months following the destruction of the New York World Trade Center on September 11, 2001, a $50 \%$ increase in acute MI was reported. ${ }^{14}$ Earthquakes are uniquely stressful disasters: they occur without warning and survivors are stressed by the threat of additional harm from aftershocks. It is uncertain how much the acute emotional trauma itself and other psychosocial factors, such as missed important medications, disrupted sleep patterns, cramped living conditions, or increased crime, each contribute to increased $\mathrm{CV}$ risk with earthquakes. ${ }^{10}$ In terms of potential mechanisms that might mediate the increased risk, there is evidence that in survivors of earthquakes, heart rate is increased and heart rate variability is reduced. These findings suggest an upset balance between the parasympathetic and sympathetic portions of the autonomic nervous system, which in turn could increase CV risk. ${ }^{10,17}$ The uncertainty of the postearthquake environment is similar to that experienced after Hurricane Katrina. In the latter, fears of flooding, fires, crime, loss of food supplies and potable water, and many tornadoes created risks of physical and psychological harm that persisted even after the hurricane had passed.

Oddly enough, along the emotional rollercoaster of life, it is not just fears of bodily harm that increase the risk of acute CV events. For example, major sporting events, such as international soccer tournaments, have also been associated with an increase in the relative risk of MI and stroke. ${ }^{18,19}$ One wonders whether the emotional effects of positive experiences in the fight to recover after Hurricane Katrina, such as the reunion with loved ones believed lost or the safe birth of children, could also have contributed to the increased incidence of acute CV events in New Orleans residents who remained after the storm.

\section{QUANTIFYING THE EFFECT OF THE HURRICANE KATRINA EXPERIENCE ON CVD}

Gautam and colleagues should be applauded for providing statistical support for a concept that seems intuitively validthat there are "infarcts (or heart attacks) beyond the storm." Although clearly there are limitations to the conclusions that can be drawn from the retrospective analysis in this unique clinical practice (which are well outlined by the authors), the data in the present report are consistent with other studies on triggers for ACS and MI and suggest, for the first time, that a natural disaster such as a major hurricane may increase the risk of acute CV events. ${ }^{3}$ Although establishing a causal relation is problematic, this study certainly suggests striking long-term medical consequences likely resulting from both PSS and a compromised health care infrastructure following Katrina.
One method for overcoming limitations of a single-center investigation is to test the reproducibility of the findings in other medical centers affected by Katrina. Along these lines, other investigators from New Orleans analyzed 1500 consecutive patients treated for ACS at Ochsner Medical Center the year before and the year following Katrina. In this analysis, there was no increase in the incidence of ACS or the absolute number of ACS patients treated. Furthermore, most clinical features of documented ACS cases remained unchanged (C.J. Lavie and R.V. Milani, unpublished observations). Nevertheless, this second investigation noted that patients who presented with ACS after Katrina were on average 3 years younger $(P<0.01)$, with a greater proportion of patients younger than 55 years $(P<0.01)$ and a smaller proportion older than 65 years $(P<0.01)$. These data suggest that a major disaster may selectively increase the risk of developing ACS in younger patients.

Of course, the quality of data from a single center can be called into question, and certainly a population-based study would be required to better address the potential causality of the associations between stressors and CV events. There is no question that residents and physicians who lived and worked in the Hurricane Katrina disaster zone understood the heavy toll that the storm exacted on patients' health, health-related quality of life, and survival.20-22 Physicians noted that, in general, many patients transitioned from a prevention-conscious health care attitude before Katrina into a survival mode after Katrina, with little attention paid to pharmacological therapy or health-related lifestyle modifications. Many patients did not know the names of their medications and had few options for reestablishing them. If patients' health care facilities were damaged or destroyed, especially institutions without an electronic medical record (EMR), then obtaining medication information from prior health care providers was virtually impossible. Many patients tried to rectify this situation, but often gave up in frustration. Other patients, who had previously received their medical care from medical facilities with robust EMRs and who purchased their medications from national pharmacies, often did not bother to refill their medications after Katrina. Many patients abandoned their diets and exercise programs, others started or resumed using tobacco products, and alcohol consumption in excessive quantities appeared to increase. Abuse of illegal drugs certainly did not decline. Undoubtedly, many patients became and remained depressed, anxious, and angry at the government, insurance companies, or even the storm itself; their faith was tested.

Even 4 years after Katrina, one of us (C.J.L.) asked a middleaged New Orleans resident who had previously survived an MI followed by coronary artery bypass surgery, "Have you been exercising?" His answer was, "I exercised daily before Katrina, but I have not yet restarted." Clearly, even 4 years after this natural disaster, local clinicians recognize the lingering toll of Katrina that extends well beyond the loss of life 
and property and continues to negatively affect the health of the population of New Orleans.

If the aforementioned gentleman's tale of changes in exercise habits is representative of the population, then this alone may portend detrimental health care consequences of Katrina that may not become obvious for years. Perhaps Edward Stanley, the third Earl of Derby, phrased it best in a 1873 speech: "Those who think they have no time for bodily exercise will sooner or later have to find time for illness." 23

\section{THE FUTURE}

Given the considerable evidence that triggering acute CV events is a legitimate and serious concern after disasters such as Hurricane Katrina, how can we prevent these medical catastrophes? Can we prevent "the infarcts beyond the storm"? Recently, Tofler and Muller suggested that prevention of acute $\mathrm{CV}$ events at times of increased risk due to a trigger can be designated as triggering acute risk prevention (Table 3)..$^{10}$

Their suggestions include general preventive strategies, including aspirin, beta-adrenergic blockers, statins, and angiotensinconverting enzyme inhibitors, all of which seem reasonable for appropriate patients. In addition, having a more robust EMR for clinics, hospitals, and pharmacies, with secondary access points should the initial ones become damaged or inaccessible, would certainly be advantageous during recovery from natural disasters. In our opinion, the most powerful strategy to prevent acute $\mathrm{CV}$ events involves regularly engaging in physical activity and exercise training $6,24-30$ and avoiding behaviors that increase risk. As such, future CVD prevention after disasters may focus on encouraging disaster victims to quit smoking and quit heavy drinking (and abusing other substances), and to again take up exercise for exercise's sake.

In the absence of natural disasters, cardiac rehabilitation and exercise training produces a $>50 \%$ reduction in major psychological risk factors, including depression, anxiety, and

\section{TABLE 3}

\section{Strategies for Triggered Acute Risk Prevention}

- Long-term general prevention

- Long-term trigger-specific prevention therapy, especially regular physical activity and exercise training as well as mental stress reducing exercises

- No intervention for added risk of trigger because the absolute risk is low

- Modification or avoidance of the trigger

- Medications that may reduce the link between trigger and its potential pathophysiological consequences (eg, aspirin, betaadrenergic blockers, statins, angiotensin-converting enzyme inhibitors, nitrates)

- Improvements in medical infrastructure (including improvements and availability of electronic medical records)

- Specific recommendation for population stressors and natural disasters

Adapted, in part, from Tofler and Muller. ${ }^{10}$ hostility.6,24-30 Small improvements in exercise capacity and overall levels of physical fitness were associated with marked reductions in depression and depression-related increased mortality risk. ${ }^{28}$ In a recent study, almost all of the benefits obtained from exercise training in a cohort with known coronary heart disease following major CV events were derived from improving exercise capacity and fitness in groups with high levels of PSS. ${ }^{29}$ Although no such intervention data are available regarding situations of natural disasters, these data, along with the findings of studies that examined triggers of acute CV events, could well imply that regular physical activity before and after a natural disaster and improvements in overall levels of fitness can help attenuate the consequences of triggers.

In summary, prophylaxis against acute $\mathrm{CV}$ events after a disaster may involve a solution (ie, exercise) that is immediately accessible, free, and broadly beneficial for both physical and mental health.6,30 As Cicero (106-43 BCE) noted, "It is exercise alone that supports the spirits and keeps the mind in vigor." ${ }_{11}$ Based on scientific research, we can add, "and also prophylaxes against acute CV events."

We applaud Gautam and colleagues ${ }^{3}$ for their stimulating research into the incidence of MI after a natural disaster. Through this research, we are once again reminded of the infinite potential for additional creative research — such as that encouraged and published by Disaster Medicine and Public Health Preparedness - to improve the health and quality of life for survivors of natural and manmade disasters. 4,5

\section{About the Authors}

Dr Lavie is with the Department of Cardiovascular Diseases; Ochsner Medical Center; Dr Gerber is with the Department of Medicine, Division of Cardiovascular Diseases, Mayo Clinic (Jacksonville, FL); and Dr Lanier is the Editor-inChief, Mayo Clinic Proceedings.

Address correspondence and reprint requests to William L. Lanier, MD, Department of Anesthesiology, Mayo Clinic, 200 First St SW, Rochester, MN 55905 (e-mail: lanier.william@mayo.edu).

Received and accepted for publication August 4, 2009

\section{Authors' Disclosures}

The authors report no conflicts of interest.

ISSN: 1935-7893 (C) 2009 by the American Medical Association and Lippincott Williams \& Wilkins.

DOI: 10.1097/DMP.0b013e3181bab1d4

\section{REFERENCES}

1. Lavie CJ. And then came Katrina: one physician's story. Emerg Med. 2005;October:10-12.

2. Discovery Channel. Surviving Katrina: facts about Katrina. http://dsc. discovery.com/convergence/katrinalfacts/facts. html. Accessed July 28, 2009.

3. Gautam S, Menachem J, Srivastav SK, et al. Effect of Hurricane Katrina on the incidence of acute coronary syndrome at a primary angioplasty in New Orleans. Disaster Med Public Health Preparedness. 2009;3:xx-xx.

4. James JJ, Subbarao I, Lanier WL. Improving the art and science of disaster medicine and public health preparedness. Mayo Clin Proc. 2008;83:559-562. 
5. Lanier WL. Letter to the editor. Disaster Med Public Health Preparedness. 2007;1:71.

6. Lavie CJ, Milani RV, Lavie TJ. Impact of cardiac rehabilitation, exercise training, and fitness on psychological distress. In: Sher L, ed. Psychological Factors and Cardiovascular Disorders: The Role of Stress and Psychosocial Influences. Hauppauge: Nova Science Publishers; 2009, pp 312 329.

7. Dimsdale JE. Psychological stress and cardiovascular disease. J Am Coll Cardiol. 2008;51:1237-1246.

8. Rozanski A, Blumental JA, Davidson KW, et al. The epidemiology, pathophysiology, and management of psychosocial risk factors in cardiac practice: the emerging field of behavioral cardiology. J Am Coll Cardiol. 2005;45:637-651.

9. Tofler GH, Stone PH, Maclure M, et al. Analysis of possible triggers of acute myocardial infarction (the MILIS study). Am J Cardiol. 1990;66: 22-27.

10. Tofler GH, Muller JE. Triggering of acute cardiovascular disease and potential preventive strategies. Circulation. 2006;114:1863-1872.

11. Culić V. Psychological factors and the triggering of acute cardiac events. In: Sher L, ed. Psychological Factors and Cardiovascular Disorders: The Role of Stress and Psychosocial Influences. New York: Nova Science Publishers; 2009, pp 39-59.

12. Milani RV, Lavie CJ. Stopping stress at its origins. Hypertension. 2007; 49:268-269.

13. Meisel SR, Kutz I, Dayan KI, et al. Effect of Iraqi missile war on incidence of acute myocardial infarction and sudden death in Israeli civilians. Lancet. 1991;338:660-661.

14. Allegra JR, Mostashari F, Rothman J, et al. Cardiac events in New Jersey after the September 11, 2001, terrorist attack. J Urban Health. 2005;82:358-363.

15. Trichopoulos D, Zavitsanos X, Katsouyanni K, et al. Psychological stress and fatal heart attack: the Athens earthquake natural experiment. Lancet. 1983;1:441-443.

16. Leor J, Kloner RA. The Northridge earthquake as a trigger for acute myocardial infarction. Am J Cardiol. 1996;77:1230-1232.

17. Huang JL, Chiou CW, Ting CT. Sudden changes in heart rate variability during the 1999 Taiwan earthquake. Am J Cardiol. 2001;87:245-248.
18. Witte DR, Bois MI, Hoes AW, et al. Cardiovascular mortality in Dutch men during 1996 European football championship: longitudinal population study. BMJ. 2000;321:1552-1554.

19. Wilbert-Lampen U, Leistner D, Greven S, et al. Cardiovascular events during World Cup soccer. N Engl J Med. 2008;358:475-483.

20. Khoo TK, Smith SA. After Katrina: quality of life among New Orleans residents with diabetes. Mayo Clin Proc. 2008;83:601.

21. Stephens KU, Grew D Sr, Chin K, et al. Excess mortality in the aftermath of Hurricane Katrina: a preliminary report. Disaster Med Public Health Preparedness. 2007;1:15-20.

22. Brunkard J, Namulanda G, Ratard R. Hurricane Katrina deaths, Louisiana, 2005. Disaster Med Public Health Preparedness. 2008;2:215-223.

23. Edward Stanley, Earl of Derby. The Conduct of Life. Address at Liverpool College, December 20, 1873.

24. Lavie CJ, Milani RV. Prevalence of anxiety in coronary patients with improvement following cardiac rehabilitation and exercise training. Am J Cardiol. 2004;93:336-339.

25. Lavie CJ, Milani RV. Effects of cardiac rehabilitation and exercise training programs on coronary patients with high levels of hostility. Mayo Clin Proc. 1999;74:959-966.

26. Lavie CJ, Milani RV. Prevalence of hostility in young coronary artery disease patients and effects of cardiac rehabilitation and exercise training. Mayo Clin Proc. 2005;80:335-342.

27. Lavie CJ, Milani RV. Adverse psychological and coronary risk profiles in young patients with coronary artery disease and benefits of formal cardiac rehabilitation. Arch Intern Med. 2006;166:1878-1883.

28. Milani RV, Lavie CJ. Impact of cardiac rehabilitation on depression and its associated mortality. Am J Med. 2007;120:799-806.

29. Milani RV, Lavie CJ. Reducing psychosocial stress: a novel mechanism of improving survival from exercise training. Am J Med. 2009. Aug 12 [Epub ahead of print].

30. Lavie CJ, Thomas RJ, Squires RW, et al. Exercise training and cardiac rehabilitation in primary and secondary prevention of coronary heart disease. Mayo Clin Proc. 2009;84:373-383.

31. Cicero. On Old Age. Vol 9, Part 2. The Harvard Classics. Shuckburgh ES, trans-ed. New York: PF Collier and Son; 1914, p 10. 